\title{
Digestibilidade e Desempenho de Coelhos Oriundos de Quatro Padrões de Alimentação até a Desmama Alimentados com Dietas Contendo Diferentes Níveis de Amido Após a Desmama
}

\section{Haroldo Garcia de Faria ${ }^{1}$, Cláudio Scapinello², Rosane Marina Peralta ${ }^{3}$, Thierry Gidenne 4 , Antonio Claudio Furlan ${ }^{2}$, Márcia Aparecida Andreazzi ${ }^{5}$}

\begin{abstract}
RESUMO - Foram conduzidos dois experimentos com o objetivo de avaliar o efeito de dietas contendo níveis de 15\% (normal) e 24\% (alto) de amido sobre digestibilidade e desempenho de coelhos em crescimento oriundos de quatro padrões de alimentação até a desmama. Para o ensaio de digestibilidade, 96 coelhos da raça Nova Zelândia Branco, de 35 a 49 dias de idade, foram distribuídos em esquema fatorial $2 \times 2 \times 2$ (ninhadas submetidas à baixa e alta disponibilidade de leite versus dois níveis de amido na dieta até a desmama versus dois níveis de amido na dieta após a desmama), com oito tratamentos e 12 repetições. Animais de ninhadas maiores apresentaram melhor aproveitamento digestivo da FDN. O maior nível de amido na dieta fornecida antes da desmama proporcionou melhor utilização digestiva da energia bruta após a desmama, e aquele fornecido após a desmama, melhor aproveitamento da matéria seca e da proteína. No ensaio de crescimento, 288 coelhos da raça Nova Zelândia Branco, de 35 a 70 dias de idade, foram distribuídos no mesmo esquema fatorial $(2 \times 2 \times 2)$, com oito tratamentos, 18 repetições e dois animais por unidade experimental. Coelhos de ninhadas mantidas com oito láparos apresentaram menor peso vivo aos 50 dias de idade, contudo, aos 70 dias de idade, não houve diferença no peso vivo entre os animais de ninhadas contendo quatro ou oito láparos. Tanto aos 50 como aos 70 dias de idade, os animais de ninhadas contendo oito láparos apresentaram melhor conversão alimentar e menor consumo diário de ração, independentemente do nível de amido nas dietas. Animais alimentados com dietas contendo nível mais alto de amido antes da desmama apresentaram maior peso vivo, tanto aos 50 como aos 70 dias de idade.
\end{abstract}

Palavras-chave: amido na dieta, desempenho, tamanho da ninhada, utilização digestiva

\section{Digestibility and Performance of Rabbits from four Feeding Patterns Until Weaning Fed Diets with Different Starch Levels After Weaning}

\begin{abstract}
Two experiments were carried out to study the effect of the normal (15\%) or high (24\%) starch level on the digestibility and performance in growing rabbits from four feeding patterns until weaning. For the digestibility assay, 96 White New Zealand from 35 to 49 days of age, were allotted to a factorial design $2 \times 2 \times 2$ (two milk intake patterns versus two starch levels before weaning versus two starch levels in diet after weaning), with eight treatments and 12 replicates. Animals from greater litters presented the best NDF digestibility coefficient. The higher starch level in diets before weaning increased the coefficient digestibility of gross energy after weaning. The high starch level in diet after weaning increased the digestive utilization of dry matter and protein. In the performance trial, 288 White New Zealand rabbit from 35 to 70 days of age were assigned to a $2 \times 2 \times 2$ factorial design (two milk intake patterns versus two starch levels in diets before weaning versus two starch levels in diet after weaning), with eight treatments, 18 replicates and two animals in each experimental unit. Rabbits from litters with eight young rabbits presented the smaller live weight at 50 days of age, however, at 70 days old there was no difference on live weight of the animals maintained in litters with four or eight young rabbits. The animals from litters with eight young rabbits, at 50 days and 70 days of age, showed the best feed conversion and the smaller daily feed intake, independently of starch level in the diets. Animals fed diets with high starch level before weaning presented greater live weight at 50 days and at 70 days of age.
\end{abstract}

Key Words: digestive utilization, litter size, performance, starch in diet

\footnotetext{
1 Zootecnista do Biotério Central - UEM - Av Colombo 5790, CEP: 87020-900, Maringá - PR (haroldogf@wnet.com.br).

2 Professor do departamento de zootecnia UEM - Av Colombo 5790, CEP: 87020-900, Maringá - PR.

3 Professora do departamento de Bioquímica - UEM - Av Colombo 5790, CEP: 87020-900, Maringá - PR.

${ }^{4}$ Pesquisador do INRA-Institut National de La Recherche Agronomique - Tolouse - França.

5 Professora do curso de Medicina Veterinária - CESUMAR - Av. Guerdner 1660, CEP: 87050-390, Maringá - PR.
} 


\section{Introdução}

Dietas para coelhos formuladas à base de alimentos de origem vegetal têm no amido a principal fonte de energia. Por outro lado, é indispensável a utilização de alimentos volumosos para atender adequadamente às exigências em carboidratos estruturais, cuja função principal é a manutenção das condições de funcionamento do trato digestivo.

Dessa forma, o balanceamento de dietas para coelhos deve considerar não apenas o volume de cada componente químico, como também a relação entre eles, em especial a dos carboidratos solúveis e estruturais.

Em razão dos elevados níveis de amido utilizados no balanceamento de dietas para coelhos, associados à redução na taxa de fibra, observam-se disfunções digestivas cada vez mais freqüentes, particularmente em animais jovens, associadas a modificações da motricidade digestiva, alterações fermentativas no ceco e diarréias (Gidenne, 1996).

Autores como Mcnitt \& Moody (1988) e Maertens $\&$ De Groote (1990) afirmam que consumo precoce de alimentos sólidos pode interferir nos resultados de desempenho, propiciando, principalmente, decréscimo da mortalidade após a desmama.

A ocorrência de enterites, principalmente logo após a desmama, é a maior causa de perdas econômicas na exploração comercial de coelhos. Segundo Peeters et al. (1984), as causas da elevada mortalidade incluem viroses, bacterioses, coccidioses, assim como fatores dietéticos, em especial o nível e a composição da fibra e sua relação com o amido. Sabe-se que mudanças na composição das dietas alteram a natureza da digesta que chega ao ceco, interferindo nos processos da fermentação. Mais precisamente, incompleta digestão do amido, que pode estar associada com o sistema enzimático pouco desenvolvido, pode representar aumento no fluxo de carboidratos que entram no ceco, alterando a atividade microbiana, especialmente em coelhos jovens (Blas et al., 1988).

Entre os fatores que interferem na digestão do amido estão sua origem botânica e seu processamento, além das condições fisiológicas ligadas à maturidade do trato digestivo. Contudo, apesar de seu efeito no valor energético das dietas para coelhos, a digestão do amido de diferentes fontes ainda é pouco estudada (Gidenne \& Perez, 1993).

Incremento geral na digestibilidade dos nutrientes ocorre quando a fibra é substituída pelo amido (Lebas et al., 1982). Trabalhos realizados com suínos, por Bengala-Freire (1989), e com aves, por Longstaff \& Mcnab (1987) e Yutste et al. (1991), demostraram que o amido de cereais é mais facilmente digerido que o amido de legumes. Estas diferenças na digestibilidade podem estar associadas com a textura do endosperma e com a relação amilose/amilopectina (Perez \& Aumaitre, 1979).

Além do efeito da fonte de amido, a digestibilidade também está diretamente associada à idade do animal, uma vez que a atividade enzimática ligada aos processos de digestão mostra importantes variações durante a vida pós-natal dos coelhos, até os 40 a 50 dias de idade (Laplace, 1978; Gidenne, 1997).

De acordo com Maertens \& De Groote (1990), consumo precoce de alimentos sólidos pode estimular a secreção enzimática, diminuindo os problemas digestivos após a desmama. Merçier (1989) também demonstrou haver forte relação entre o consumo de alimento e a atividade enzimática no trato digestivo de coelhos.

Contudo, Scapinello et al. (1999), estudando a capacidade digestiva de coelhos durante o período pós-desmama, de acordo com o padrão de consumo leite/alimento sólido antes da desmama, concluíram que a mudança no padrão no pré-desmame alimentar não proporcionou alterações na capacidade digestiva no pós-desmama, avaliada pela atividade enzimática da amilase e maltase no jejuno e íleo de coelhos em crescimento.

Portanto, o equilíbrio entre o máximo desempenho e o bom estado sanitário do trato digestivo ainda é um desafio na nutrição de coelhos.

Objetivou-se, com este trabalho, determinar os coeficientes de utilização digestiva de nutrientes e da energia de dietas com níveis normal ou alto de amido e avaliar o desempenho de coelhos de ninhadas mantidas com diferentes padrões de alimentação durante a fase de amamentação.

\section{Material e Métodos}

Para avaliar a capacidade de utilização digestiva da matéria seca, proteína bruta, energia bruta, amido, fibra em detergente neutro e fibra em detergente ácido das dietas experimentais com níveis normais $(15 \%)$ ou alto $(24 \%)$ de amido após a desmama, foram utilizados 96 coelhos da raça Nova Zelândia Branco, com 35 dias de idade, em um ensaio de digestibilidade. Os coelhos eram de ninhadas mantidas em quatro diferentes padrões de alimentação até a

R. Bras. Zootec., v.33, n.5, p.1172-1180, 2004 
desmama, submetidas à baixa e alta disponibilidade de leite, por meio da variação do número de láparos na ninhada (quatro ou oito animais). Os animais receberam dietas com níveis normal $(15 \%)$ ou alto (24\%) de amido até o desmame e foram redistribuídos em esquema fatorial, utilizando as mesmas dietas com níveis normal ou alto de amido após a desmama (Tabela 1). Os animais desmamados foram distribuídos, individualmente, em gaiolas metabólicas providas de bebedouros automáticos, comedouros semi-automáticos e dispositivo para coleta de fezes. O delineamento utilizado foi inteiramente casualizado em esquema fatorial $2 \times 2 \times 2$ (ninhadas submetidas à baixa e alta disponibilidade de leite versus dois níveis de amido em dietas até a desmama versus dois níveis de amido em dietas após a desmama), com oito tratamentos e 12 repetições. As dietas, peletizadas a seco, foram fornecidas à vontade durante as fases de adaptação e de coleta de fezes.

O experimento teve duração de 14 dias - 10 de adaptação às rações e às gaiolas e quatro para coleta de fezes, utilizando-se a metodologia padronizada para ensaios de digestibilidade in vivo (Perez et al., 1995).

As fezes de cada animal foram coletadas em sua totalidade, no período da manhã, acondicionadas em sacos plásticos e armazenadas em freezer a $-18^{\circ} \mathrm{C}$. Posteriormente, ao final do experimento, foram pesadas, homogeneizadas e colocadas em estufas de ventilação forçada a $60^{\circ} \mathrm{C}$, durante 72 horas. Em seguida, foram moídas e acondicionadas em vidros devidamente identificados, para análises laboratoriais de matéria seca (MS), proteína bruta (PB), fibra em detergente neutro (FDN), fibra em detergente ácido (FDA) e energia bruta (EB), de acordo com Silva (1990), e de amido, pelo método enzimático adaptado por Pereira \& Rossi (1995), para cálculo dos respectivos coeficientes de digestibilidade.

No experimento de desempenho, foram utilizados 288 coelhos da raça Nova Zelândia Branco, metade de cada sexo, de 35 a 70 dias de idade, de ninhadas mantidas em quatro diferentes padrões de alimentação até a desmama, submetidas à baixa e alta disponibilidade de leite, por meio da variação do número de láparos na ninhada (quatro ou oito láparos), sob dietas contendo níveis normal ou alto de amido até a desmama, redistribuídos em esquema fatorial, utilizando-se as mesmas dietas com níveis normal ou alto de amido após a desmama (Tabela 1). Os animais desmamados foram alojados em gaiolas de arame galvanizado com $0,24 \mathrm{~m}^{2}$ providas de bebedouro
Tabela 1 - Composição percentual das dietas experimentais

Table 1 - Percentage composition of the experimental diets

\begin{tabular}{|c|c|c|c|}
\hline $\begin{array}{l}\text { Ingredientes } \\
\text { Ingredient }\end{array}$ & $\begin{array}{l}\text { Unidade } \\
\text { Unit }\end{array}$ & $\begin{array}{c}\text { Amido } \\
\text { normal } \\
\text { Normal } \\
\text { starch }\end{array}$ & $\begin{array}{c}\text { Alto } \\
\text { amido } \\
\text { High } \\
\text { starch }\end{array}$ \\
\hline Milho & $\mathrm{kg}$ & 14,11 & 32,50 \\
\hline $\begin{array}{l}\text { Corn } \\
\text { Farelo de soja } \\
\text { Soybean meal }\end{array}$ & $\mathrm{kg}$ & 12,60 & 16,00 \\
\hline $\begin{array}{l}\text { Farelo de trigo } \\
\text { Wheat meal }\end{array}$ & $\mathrm{kg}$ & 25,00 & 9,50 \\
\hline $\begin{array}{l}\text { Feno de alfafa } \\
\text { Alfalfa hay }\end{array}$ & $\mathrm{kg}$ & 28,00 & 27,00 \\
\hline $\begin{array}{l}\text { Feno de aveia } \\
\text { Oats hay }\end{array}$ & $\mathrm{kg}$ & 15,52 & 9,00 \\
\hline $\begin{array}{l}\text { Sal comum } \\
\text { Common salt }\end{array}$ & $\mathrm{kg}$ & 0,40 & 0,40 \\
\hline $\begin{array}{l}\text { Fosfato bicálcico } \\
\text { Dicalcium phosphate }\end{array}$ & $\mathrm{kg}$ & 0,10 & 0,34 \\
\hline $\begin{array}{l}\text { Calcário } \\
\text { Limestone }\end{array}$ & $\mathrm{kg}$ & 0,70 & 0,70 \\
\hline $\begin{array}{l}\text { DL-Metionina } \\
\text { DL-Methionine }\end{array}$ & $\mathrm{kg}$ & 0,07 & 0,06 \\
\hline $\begin{array}{l}\text { Mist. vit+min }{ }^{1} \\
\text { Premix vit }+ \text { min. }^{1}\end{array}$ & $\mathrm{~kg}$ & 0,50 & 0,50 \\
\hline $\begin{array}{l}\text { Óleo de soja } \\
\text { Soybean oil }\end{array}$ & $\mathrm{kg}$ & 3,00 & - \\
\hline $\begin{array}{l}\text { Casca de arroz } \\
\text { Rice hulls } \\
\end{array}$ & $\mathrm{kg}$ & - & 4,00 \\
\hline Total & $\mathrm{kg}$ & 100 & 100 \\
\hline
\end{tabular}

Composição analisada com base na matéria natural

Analyzed composition in natural matter basis

$\begin{array}{llll}\text { Matéria seca } & \% & 90,80 & 90,40\end{array}$

Dry matter

Amido

Starch

Proteína bruta
Crude protein

90,40

FDN

$N D F$

FDA

$A D F$

Cálcio

Calcium

Fósforo

Phosphorus

Lisina*

Lysine

Metionina+cistina*

Methionine+Cystine

Energia digestível*

$\%$

15,27

24,07

Digestible energy

${ }^{1}$ Nuvital, composição por kg do produto: Vit A, $600.000 \mathrm{UI}$; Vit D, $100.000 \mathrm{UI}$; Vit E, $8.000 \mathrm{mg}$; Vit K3, $200 \mathrm{mg}$; Vit B1, $400 \mathrm{mg}$; Vit B2, $600 \mathrm{mg}$; Vit B6, $200 \mathrm{mg}$; Vit B12, $2.000 \mathrm{mcg}$; Ac. Pantotênico, $2.000 \mathrm{mg}$; Colina, $70.000 \mathrm{mg}$; Ferro, $8.000 \mathrm{mg}$; Cobre, $1.200 \mathrm{mg}$; Cobalto, $200 \mathrm{mg}$; Manganês, $8.600 \mathrm{mg}$; Zinco, $12.000 \mathrm{mg}$; lodo, $64 \mathrm{mg}$; Selênio, $16 \mathrm{mg}$; Metionina, $120.000 \mathrm{mg}$; Antioxidante, $20.000 \mathrm{mg}$.

1 Vitamin-mineral premix (Nuvital) composition per kg: Vit A, $600.000 \mathrm{UI}$; Vit D, 100.000 Ul; Vit E, $8.000 \mathrm{mg}$; Vit K3, $200 \mathrm{mg}$; Vit B1,400 mg; Vit B2, $600 \mathrm{mg}$; Vit B6, $200 \mathrm{mg}$ : Vit B12, $2.000 \mathrm{mcg}$ : Panthotenic ac, $2.000 \mathrm{mg}$; Choline, $70.000 \mathrm{mg}$; Iron, $8.000 \mathrm{mg}$; Copper, $1.200 \mathrm{mg}$; Cobalt, $200 \mathrm{mg}$; Manganese, 8.600 mg; Zinc, 12.000 mg; lodine, 64 mg; Selenium, 16 mg; Methionine, $120.000 \mathrm{mg}$; Sinox, $20.000 \mathrm{mg}$.

* De acordo com a composição dos alimentos.

* According to the feeds composition.

\section{R. Bras. Zootec., v.33, n.5, p.1172-1180, 2004}


automático e comedouro semi-automático de chapa galvanizada, localizadas em galpão de alvenaria, com cobertura de telha francesa, pé-direito de 3,0 m, piso em alvenaria, paredes laterais de $50 \mathrm{~cm}$ em alvenaria e o restante em tela e cortina de plástico, para controle de ventos.

Os animais foram distribuídos em delineamento inteiramente casualizado, em esquema fatorial $2 \times 2 \times 2$ (ninhadas submetidas à baixa e alta disponibilidade de leite versus dois níveis de amido até a desmama versus dois níveis de amido após a desmama), com oito tratamentos, 18 repetições e dois animais por unidade experimental. As dietas experimentais, peletizadas a seco, e o fornecimento de rações e água foram ad libitum.

Os coelhos foram pesados no início do experimento ( 35 dias de idade), aos 50 dias e no final do experimento (70 dias de idade). As rações fornecidas e as sobras também foram pesadas a cada pesagem dos animais.

As características avaliadas referentes à carcaça foram obtidas com a carcaça quente, sem a cabeça e vísceras comestíveis. Os parâmetros de desempenho analisados foram consumo de ração diário (CRD), ganho de peso diário (GPD), conversão alimentar (CA), peso de carcaça (PC) e rendimento de carcaça (RC).

Os dados dos coeficientes de digestibilidade e do desempenho dos coelhos da desmama ao abate foram submetidos à análise de variância, utilizando o programa SAEG (1997). O modelo utilizado para análises dos dados é apresentado abaixo:

$\mathrm{Y}_{\mathrm{ijk} l}=\mu+\mathrm{N}_{\mathrm{i}}+\mathrm{A}_{\mathrm{j}}+\mathrm{B}_{\mathrm{k}}+\mathrm{NA}_{\mathrm{ij}}+\mathrm{NB}_{\mathrm{ik}}+\mathrm{AB}_{\mathrm{jk}}+\mathrm{e}_{\mathrm{ijk} \mathrm{l}}$

em que $\mathrm{Y}_{\mathrm{ijkl}}=$ observação relativa ao indivíduo $l$, da ninhada com número $k$ de láparos, recebendo o nível $j$ de amido nas dietas até a desmama e nível $i$ de amido nas dietas após a desmama; $\mu=$ média geral de cada característica; $\mathrm{N}_{\mathrm{i}}=$ efeito do nível $i$ de amido nas dietas após a desmama, sendo $i=1$ e $2\left(i_{1}=\operatorname{dietas}\right.$ com $15 \%$ de amido, $i_{2}=$ dietas com $24 \%$ de amido); $\mathrm{A}_{\mathrm{j}}=$ efeito do nível de amido nas dietas fornecidas até a desmama, sendo $j=1$ e $2\left(j_{l}=\operatorname{dietas}\right.$ com $15 \%$ amido e $j_{2}=$ dietas com $24 \%$ amido); $\mathrm{B}_{\mathrm{k}}=$ efeito do número $k$ de láparos nas ninhadas, sendo $k=1$ e 2 ( $k_{1}=$ ninhadas com quatro láparos e $k_{2}=$ ninhadas com oito láparos); $\mathrm{NA}_{\mathrm{ij}}=$ efeito da interação entre os níveis $i$ de amido em dietas após a desmama e $j$ de amido em dietas antes da desmama; $\mathrm{NB}_{\mathrm{ik}}=$ efeito da interação entre o nível $i$ de amido em dietas após desmama e o número $k$ de láparos nas ninhadas até a desmama; $\mathrm{AB}_{\mathrm{jk}}=$ efeito da interação entre $\mathrm{o}$ nível $j$ de amido nas dietas fornecidas até a desmama e o número $k$ de láparos nas ninhadas até a desmama; $\mathrm{e}_{\mathrm{ijk}}=$ erro aleatório associado a cada observação.

Para comparação das médias, foi utilizado o teste $\mathrm{F}$, a $5 \%$.

\section{Resultados e Discussão}

Foi observada interação $(\mathrm{P}<0,05)$ entre o tamanho da ninhada até a desmama e o nível de amido nas dietas fornecidas após a desmama para os coeficientes de digestibilidade aparente da matéria seca (CDMS) e da proteína bruta (CDPB). Independentemente do tamanho da ninhada em que os láparos foram mantidos até a desmama, os maiores CDMS e CDPB foram observados em animais que receberam a dieta com alto nível de amido após a desmama (Tabela 2). Entretanto, a utilização de dietas com níveis alto ou normal de amido antes da desmama não influenciou $(\mathrm{P}>0,05)$ a capacidade de utilização digestiva da matéria seca e da proteína bruta após a desmama, que apresentaram médias para matéria seca de $66,2 \%$, para dietas com alto teor de amido, e de $66,5 \%$ para dietas com baixo teor de amido. Para a proteína, foram obtidos valores de 81,7 e $81,9 \%$, respectivamente.

Os coeficientes de digestibilidade dos demais nutrientes e da energia, de acordo com o tamanho da ninhada em que os láparos foram mantidos até a desmama, bem como os níveis de amido utilizados nas dietas antes e após o desmame, encontram-se na Tabela 3. Não foram observadas interações $(P>0,05)$ entre o tamanho da ninhada e os níveis de amido nas dietas utilizadas antes e após a desmama sobre os coeficientes de digestibilidade aparentes de FDN, FDA, energia bruta e amido.

Apenas o CDFDN obtido com os coelhos de ninhadas com oito láparos foi maior $(\mathrm{P}<0,05) \mathrm{em}$ relação àqueles mantidos em ninhadas com apenas quatro láparos. Possivelmente, este resultado estaria relacionado ao consumo mais precoce e em maior quantidade de alimentos sólidos pelos animais mantidos em ninhadas mais numerosas até os 30 dias de idade, o que estimularia a atividade microbiana do ceco, antecipando a maturidade digestiva deste segmento do trato digestivo.

Foi observado também que os animais sob dieta com teor mais elevado de amido, antes da desmama,

\section{R. Bras. Zootec., v.33, n.5, p.1172-1180, 2004}


independentemente do tamanho da ninhada, apresentaram, durante o experimento, maior $(\mathrm{P}<0,05)$ $\mathrm{CDEB}$ em relação àqueles alimentados com dietas contendo nível normal de amido. Resultados semelhantes também foram observados com a dieta mais rica em amido, fornecida após a desmama, independentemente do padrão alimentar até a desmama.

Jehl et al. (1998), avaliando dietas contendo níveis de amido de $2,5,9,8,19,6,27,7$ e 37,4\% e níveis de
FDN de 42,$3 ; 36,9 ; 31,1 ; 27,2$ e $19,4 \%$, encontraram valores de digestibilidade da energia de 59,$5 ; 67,0$; 76,$6 ; 77,0$ e $84,4 \%$ e da proteína de 68,$2 ; 74,4 ; 84,2$; 83,7 e $89,9 \%$, respectivamente. Os autores afirmam que a digestibilidade da energia está diretamente correlacionada com os teores de FDN e FDA, em que a redução em 1 ponto percentual nos níveis FDN e FDA levaria à melhora na digestibilidade da energia de 1,1 e 1,8 , respectivamente. Relações semelhantes

Tabela 2 - Coeficientes de digestibilidade da matéria seca (CDMS) e da proteína bruta (CDPB) de dietas contendo níveis alto (24\%) ou normal (15\%) de amido, em coelhos desmamados de ninhadas mantidas em quatro diferentes padrões de alimentação durante a lactação

Table 2 - Digestibility of coefficients of dry matterr (DCDM) and crude protein (DCCP) of diets containing high (24\%) or normal starch (15\%) levels for weaned rabbits from litter under four different feeding patterns during the lactation

\begin{tabular}{|c|c|c|c|c|c|}
\hline \multirow[b]{3}{*}{$\begin{array}{l}\text { Amido após desmama }(\%) \\
\text { Starch level post weaning }(\%)\end{array}$} & \multicolumn{4}{|c|}{$\begin{array}{c}\text { Tamanho da ninhada }\left(\mathrm{N}^{\circ} \text { láparos }\right) \\
\text { Litter size ( } N . \text { young rabbits })\end{array}$} & \multirow[b]{3}{*}{$\mathrm{CV}(\%)$} \\
\hline & \multicolumn{2}{|c|}{4} & \multicolumn{2}{|c|}{8} & \\
\hline & 15 & 24 & 15 & 24 & \\
\hline $\operatorname{CDMS}(\%)^{1}$ & $64,6 \mathrm{~b}$ & $69,2 \mathrm{a}$ & $64,1 b$ & $67,5 a$ & 3,81 \\
\hline $\begin{array}{l}D C D M \\
\operatorname{CDPB}(\%)^{1} \\
D C C P\end{array}$ & $80,1 b$ & $82,5 a$ & $81,6 b$ & $82,8 \mathrm{a}$ & 1,75 \\
\hline
\end{tabular}

${ }^{1}$ Médias com letras diferentes no sentido de linha diferem $(P<0,05)$ pelo teste $F$.

${ }^{1}$ Means, in line, followed by different letters differ $(P<.05)$ by $F$ test.

Tabela 3 - Coeficientes de digestibilidade de fibra em detergente neutro (CFDN), fibra em detergente ácido (CFDA), energia bruta (CDEB) e amido (CDA), de acordo com o tamanho da ninhada até a desmama e os níveis de amido utilizados em dietas antes e após a desmama

Table 3 - Coefficients of digestibility of neutral detergent fiber (DCNDF), acid detergent fiber (DCADF), gross energy (DCGE) and starch (DCS), according to the litter size until weaning and the starch levels in diets before and post weaning

\begin{tabular}{|c|c|c|c|c|c|c|c|c|}
\hline & & & \multicolumn{4}{|c|}{$\begin{array}{c}\text { Nível de amido (\%) } \\
\text { Starch level }(\%)\end{array}$} & \multirow{3}{*}{$\begin{array}{l}\text { Médias } \\
\text { Means }\end{array}$} & \multirow{3}{*}{$\mathrm{CV}(\%)$} \\
\hline & \multicolumn{2}{|c|}{$\begin{array}{c}\text { Tamanho da } \\
\text { ninhada } \\
\text { Litter size }\end{array}$} & \multicolumn{2}{|c|}{$\begin{array}{c}\text { Antes da } \\
\text { desmama } \\
\text { Before weaning }\end{array}$} & \multicolumn{2}{|c|}{$\begin{array}{l}\text { Pós-desmama } \\
\text { Post-weaning }\end{array}$} & & \\
\hline & 4 & 8 & 15 & 24 & 15 & 24 & & \\
\hline $\begin{array}{l}\text { CDFDN }(\%)^{1} \\
D C N D F\end{array}$ & $36,3 b$ & $37,6 a$ & 37,3 & 36,6 & 36,9 & 37,0 & 36,9 & 7,82 \\
\hline $\begin{array}{l}\text { CDFDA }(\%) \\
D C A D F\end{array}$ & 29,2 & 29,3 & 29,5 & 28,9 & 29,6 & 28,9 & 29,3 & 8,76 \\
\hline $\begin{array}{l}\operatorname{CDEB}(\%)^{2} \\
D C G E\end{array}$ & 66,7 & 67,2 & $66,3 b$ & $67,6 a$ & $65,9 b$ & $68,0 \mathrm{a}$ & 66,9 & 4,85 \\
\hline $\begin{array}{l}\operatorname{CDA}(\%) \\
D C S\end{array}$ & 96,0 & 96,1 & 96,1 & 96,1 & 96,0 & 96,1 & 96,1 & 0,55 \\
\hline
\end{tabular}

\section{R. Bras. Zootec., v.33, n.5, p.1172-1180, 2004}


entre a digestibilidade da ração e os teores de FDN e FDA também foram observadas por Gidenne et al. (1991). Possivelmente, esta também deve ter sido a causa da melhora na digestibilidade da energia no presente experimento, tendo em vista a elevada digestibilidade do amido, independentemente dos níveis deste componente nas dietas e da eficiência dos coelhos em utilizar a gordura das dietas.

Resultados semelhantes de coeficientes de digestibilidade da proteína bruta e da energia foram obtidos por Gidenne \& Perez (1993) para dieta contendo $29 \%$ de amido, 28,3\% de FDN e $17,1 \%$ de FDA, sendo o milho a principal fonte de amido.

Gidenne et al. (1998), avaliando dietas contendo 10,$0 ; 21,0$ e $29,5 \%$ de amido e 39,$0 ; 31,0$ e $23,8 \%$ de FDN, encontraram valores de digestibilidade para a energia de 63,$3 ; 71,4$ e $76,8 \%$ e para a proteína de 70,$9 ; 76,6$ e $78,5 \%$, respectivamente, demonstrando também a maior disponibilidade de nutrientes em dietas mais ricas em amido e com menores teores de componentes de fibra.

Xiccato et al. (1998), estudando a relação amido/ fibra para coelhos em dietas para coelhos em crescimento, obtiveram coeficientes de digestibilidade da matéria seca, proteína, energia e amido de 61,4; 73,$4 ; 60,5$; e $98,2 \%$, respectivamente, para dietas contendo $22 \%$ de amido e $34 \%$ de FDN, e de 54,9 ; 70,$4 ; 54,8$; e $98,4 \%$, respectivamente, para dietas contendo $17 \%$ de amido e $37 \%$ de FDN, corroborando os resultados encontrados neste trabalho.

É importante ressaltar que os resultados mostram a possibilidade de antecipar os processos de maturidade do trato digestivo dos láparos por meio do manejo de dietas que estimulem precocemente a liberação de enzimas ligadas à digestão de nutrientes de dietas sólidas. Este aspecto vem ao encontro das recentes preocupações de pesquisadores na área de cunicultura, tendo em vista suas ligações com distúrbios digestivos responsáveis por elevadas taxas de mortalidade na fase peri-desmama.

Não houve interação $(P>0,05)$ entre o tamanho das ninhadas e os níveis de amido nas dietas fornecidas, na pré e pós-desmama, para as características de desempenho dos coelhos de 35 a 50 dias de idade (Tabela 4).

O ganho de peso diário e a conversão alimentar foram melhores $(\mathrm{P}<0,05)$ e o consumo de ração diário, menor $(\mathrm{P}<0,05)$ para os animais de ninhadas mantidas com oito láparos até a desmama. Apesar destes resultados, o peso vivo aos 50 dias de idade ainda foi maior $(\mathrm{P}<0,05)$ para coelhos desmamados de ninhadas com apenas quatro láparos, tendo em vista o maior peso à desmama; fato que contribuiu para o maior consumo de ração $(\mathrm{P}<0,05)$ pelos animais mantidos em ninhadas menores.

Scapinello et al. (1999) também verificaram que coelhos provindos de ninhadas pequenas (quatro láparos) apresentaram maior peso ao desmame (32 dias), que foi mantido até 42 dias de idade, quando comparados com coelhos de ninhadas maiores (10 láparos).

Em relação à velocidade de ganho de peso após a desmama, pode-se inferir que a melhor adaptação aos alimentos sólidos dos animais mantidos em ninhadas maiores, haja vista o consumo mais precoce e em maior volume contribuiu para os resultados obtidos.

Mcnitt \& Moody (1988) ressaltam a importância da ingestão precoce de alimentos sólidos pelos láparos, já que este fator tem influência positiva no peso à desmama, bem como no desempenho após desmama.

Analisando os efeitos dos níveis de amido, embora não tenha sido observada diferença $(\mathrm{P}>0,05)$ no ganho de peso e no consumo de ração, os animais que receberam a dieta mais rica em amido antes da desmama apresentaram maior peso vivo aos 50 dias de idade e pior conversão alimentar $(\mathrm{P}<0,05)$ no período de 35 a 50 dias de idade.

Em relação aos níveis de amido avaliados nas dietas após a desmama, os animais alimentados com a dieta contendo $24 \%$ de amido apresentaram melhor conversão alimentar $(\mathrm{P}<0,05)$ até os 50 dias de idade, reflexo do menor consumo de ração neste período $(\mathrm{P}<0,05)$, uma vez que o ganho de peso diário foi idêntico ao dos animais que receberam a dieta com $15 \%$ de amido.

Deve ser destacado que, apesar de as dietas serem formuladas com níveis de energia semelhantes, os animais apresentaram menor consumo diário e melhora na conversão alimentar, quando a dieta fornecida antes da desmama apresentou nível de amido mais baixo. Possivelmente, este fato estaria relacionado ao teor de óleo contido nesta dieta (3\%), reduzindo a taxa de passagem e melhorando a eficiência digestiva. De acordo com Mateos \& Sell (1981) e Wiseman (1984), a velocidade do trânsito digestivo é reduzida pela presença de lipídios na dieta e, por conseguinte, há maior contato entre enzimas digestivas e conteúdo do trato digestivo, melhorando a absorção de nutrientes.

Não houve diferença $(P>0,05)$ no peso vivo aos

\section{R. Bras. Zootec., v.33, n.5, p.1172-1180, 2004}


50 dias de idade, independentemente do nível de amido nas dietas fornecidas após a desmama. Por outro lado, Blas et al. (1994) afirmam que dietas com níveis superiores a $15 \%$ de amido não são recomendáveis, uma vez que o excesso de amido pode causar problemas digestivos, comprometendo o desempenho dos animais.

Contrariando as observações desses autores, não foram observados problemas de ordem digestiva que tenham levado à mortalidade dos animais, tanto em relação ao nível de amido nas dietas antes ou após a desmama, ou quanto ao número de animais mantidos nas ninhadas até o desmame.

Fica claro que não é apenas o nível de amido nas dietas que deve ser considerado, mas também sua relação com outros componentes da dieta, em especial com os componentes da fibra.

As médias de peso vivo aos 70 dias de idade, o desempenho no período de 35 a 70 dias de idade e o peso e rendimento de carcaça quente sem cabeça, de acordo com o tamanho da ninhada até a desmama e os níveis de amido em dietas fornecidas tanto antes como após a desmama, são apresentados na Tabela 5.

Não foram observadas interações $(\mathrm{P}>0,05)$ entre o tamanho da ninhada e os níveis de amido nas dietas fornecidas antes e após a desmama para as características de desempenho e de carcaça, no período de 35 a 70 dias de idade.

O maior ganho de peso diário $(\mathrm{P}<0,05)$ dos animais de ninhadas maiores (com oito animais), durante o período total do experimento, igualou-se ao peso vivo aos 70 dias de idade, que, a princípio, foi maior, tanto na desmama quanto aos 50 dias de idade, para os animais de ninhadas com apenas quatro láparos. Além dos melhores resultados de ganho de peso, os láparos de ninhadas maiores apresentaram maior consumo diário de ração e melhor conversão alimentar no período de 35 a 70 dias de idade $(\mathrm{P}<0,05)$.

Ficou evidenciado ganho de peso compensatório, após a desmama, para os animais de ninhadas maiores, independentemente do nível de amido utilizado nas dietas após a desmama. Além deste aspecto, técnicas de manejo que permitam consumo precoce de alimentos sólidos, antecipando a maturidade do trato

Tabela 4 - Peso vivo aos 35 (PV35) e aos 50 dias de idade (PV50) e ganho de peso diário (GPD), consumo de ração diário (CRD) e conversão alimentar (CA) de coelhos de 35 a 50 dias de idade, de acordo com o tamanho da ninhada até a desmama e os níveis de amido utilizados em dietas antes e após a desmama

Table 4 - Live Weight at 35 (LW35) and 50 days old (LW50) and daily weight gain (DWG), daily feed intake (DFI) and feed conversion (FC), of rabbits from 35 to 49 days old, according to the litter size until weaning and starch levels in diets before and post weaning

\begin{tabular}{|c|c|c|c|c|c|c|c|c|}
\hline & \multicolumn{6}{|c|}{$\begin{array}{l}\text { Nível de amido (\%) } \\
\text { Starch level (\%) }\end{array}$} & \multirow{3}{*}{$\begin{array}{l}\text { Médias } \\
\text { Means }\end{array}$} & \multirow{3}{*}{$\mathrm{CV}(\%)$} \\
\hline & \multicolumn{2}{|c|}{$\begin{array}{l}\text { Tamanho da } \\
\text { ninhada } \\
\text { Litter size }\end{array}$} & \multicolumn{2}{|c|}{$\begin{array}{c}\text { Antes da } \\
\text { desmama } \\
\text { Before weaning }\end{array}$} & \multicolumn{2}{|c|}{$\begin{array}{l}\text { Pós-desmama } \\
\text { Post-weaning }\end{array}$} & & \\
\hline & 4 & 8 & 15 & 24 & 15 & 24 & & \\
\hline $\begin{array}{l}\text { PV35 }(\mathrm{g})^{1} \\
\text { LW } 35\end{array}$ & $850 \mathrm{a}$ & $694 b$ & $735 b$ & $810 \mathrm{a}$ & $775 a$ & $770 \mathrm{a}$ & 772 & 7,9 \\
\hline $\begin{array}{l}\text { PV50 }(\mathrm{g})^{1} \\
\text { LW } 50\end{array}$ & $1451 \mathrm{a}$ & $1331 b$ & $1361 b$ & $1421 \mathrm{a}$ & 1384 & 1399 & 1391 & 6,7 \\
\hline $\begin{array}{l}\operatorname{GPD}(\mathrm{g})^{2} \\
D W G\end{array}$ & $43 b$ & $45 \mathrm{a}$ & 45 & 44 & 44 & 45 & 44 & 10,5 \\
\hline $\begin{array}{l}\mathrm{CRD}(\mathrm{g})^{3} \\
D F I\end{array}$ & $98 \mathrm{a}$ & $93 b$ & 94 & 97 & $98 b$ & $93 a$ & 95 & 10,0 \\
\hline $\begin{array}{l}\mathrm{CA}^{4} \\
F C \\
\end{array}$ & $2,29 \mathrm{~b}$ & $2,06 a$ & $2,11 \mathrm{a}$ & $2,23 b$ & $2,26 b$ & $2,08 \mathrm{a}$ & 2,17 & 9,7 \\
\hline
\end{tabular}

${ }^{1}$ Efeito do tamanho da ninhada e nível amido antes da desmama $(\mathrm{P}<0,05)$ pelo teste $\mathrm{F}$.

1 Effect of litter size and starch level before weaning $(P<.05)$ by $F$ test.

2 Efeito do tamanho da ninhada $(P<0,05)$, pelo teste $F$.

2 Effect of litter size $(P<.05)$ by $F$ test.

3 Efeito do tamanho da ninhada e nível amido após desmama $(P<0,05)$ pelo teste $F$.

${ }^{3}$ Effect of litter size and starch level post-weaning $(P<.05)$ by $F$ test.

4 Efeito do tamanho da ninhada e nível amido antes e pós-desmama e grupo $(P<0,05)$ pelo teste $F$.

${ }^{4}$ Effect of litter size and starch level before and post-weaning and group $(P<.05)$ by $F$ test. 
Tabela 5 - Peso vivo aos 70 dias de idade (PV70), ganho de peso diário (GPD), consumo de ração diário (CRD), conversão alimentar de coelhos de 35 a 70 dias de idade e peso de carcaça $(P C)$ e rendimento de carcaça $(R C)$ de coelhos abatidos aos 70 dias de idade, de acordo com o tamanho da ninhada até a desmama e os níveis de amido utilizados em dietas antes e após a desmama

Table 5 - Live weight at 70 days old (LW 70) and daily weight gain (DWG), daily feed intake (DFI), feed conversion (FC) of rabbits from 35 to 70 days old and carcass weight (CW) and carcass yield (CY) of rabbits slaughtered at 70 days old, according to the litter size until weaning and the starch levels used in diets before and post weaning

\begin{tabular}{|c|c|c|c|c|c|c|c|c|}
\hline & \multicolumn{6}{|c|}{$\begin{array}{l}\text { Nível de amido (\%) } \\
\text { Starch level (\%) }\end{array}$} & \multirow{3}{*}{$\begin{array}{l}\text { Médias } \\
\text { Means }\end{array}$} & \multirow{3}{*}{$\mathrm{CV}(\%)$} \\
\hline & \multicolumn{2}{|c|}{$\begin{array}{c}\text { Tamanho da } \\
\text { ninhada } \\
\text { Litter size }\end{array}$} & \multicolumn{2}{|c|}{$\begin{array}{c}\text { Antes da } \\
\text { desmama } \\
\text { Before weaning } \\
\end{array}$} & \multicolumn{2}{|c|}{$\begin{array}{l}\text { Pós-desmama } \\
\text { Post-weaning }\end{array}$} & & \\
\hline & 4 & 8 & 15 & 24 & 15 & 24 & & \\
\hline $\operatorname{PV70}(\mathrm{g})^{1}$ & 2026 & 1966 & $1961 b$ & 2031a & 1988 & 2004 & 1996 & 9,4 \\
\hline $\begin{array}{l}L W \\
\operatorname{GPD}(\mathrm{g})^{2} \\
D W G\end{array}$ & $34,6 b$ & $37,4 \mathrm{a}$ & 36,0 & 35,9 & 35,7 & 36,3 & 36 & 14,5 \\
\hline $\begin{array}{l}\mathrm{CRD}(\mathrm{g})^{2} \\
\mathrm{DFi}\end{array}$ & $107 \mathrm{a}$ & $103 b$ & 105 & 105 & 106 & 104 & 105 & 12,0 \\
\hline $\begin{array}{l}\mathrm{CA}^{2} \\
\mathrm{FC}\end{array}$ & $3,26 \mathrm{~b}$ & $2,77 \mathrm{a}$ & 3,02 & 3,01 & 3,02 & 3,01 & 3,01 & 26,5 \\
\hline $\mathrm{PC}(\mathrm{g})^{2}$ & $1011 \mathrm{a}$ & $963 b$ & 973 & 1000 & 984 & 990 & 987 & 10,2 \\
\hline $\begin{array}{l}F C \\
\mathrm{RC}(\%)^{2} \\
C Y\end{array}$ & $50 \mathrm{a}$ & $48 b$ & 50 & 49 & 49 & 49 & 49 & 4,2 \\
\hline
\end{tabular}

${ }^{1}$ Efeito do nível amido antes da desmama. $(\mathrm{P}<0,05)$ pelo teste $\mathrm{F}$.

1 Effect of starch level before weaning $(P<.05)$ by $F$ test.

${ }^{2}$ Efeito do tamanho da ninhada $(\mathrm{P}<0,05)$ pelo teste $\mathrm{F}$.

2 Effect of litter size $(P<.05)$ by $F$ test.

digestivo, podem melhorar o aproveitamento dos nutrientes, como observado no experimento de digestibilidade, com reflexos positivos no desempenho após a desmama.

Apesar de a diferença para o peso vivo aos 70 dias de idade entre os animais de ninhadas desmamadas com oito ou quatro láparos não ter sido significativa $(\mathrm{P}>0,05)$, tanto o peso como o rendimento de carcaça quente sem cabeça foram maiores $(\mathrm{P}<0,05)$ para os animais de ninhadas menores.

Com relação aos níveis de amido, os animais alimentados com dieta contendo $24 \%$ de amido antes da desmama apresentaram melhor peso vivo $(\mathrm{P}<0,05)$ aos 70 dias de idade. As demais características de desempenho e de carcaça não foram influenciadas $(\mathrm{P}>0,05)$ pelos níveis de amido utilizados nas dietas antes e após a desmama.

Estes resultados estão de acordo com os obtidos por Xiccato et al. (1998), que, trabalhando com coelhos de 39 a 80 dias de idade, sob dietas com níveis de 16,3 até $21,8 \%$ de amido, concluíram que estes níveis de amido não influenciaram o desempenho dos animais.

\section{Conclusões}

Nas condições em que o experimento foi conduzido, pode-se concluir que animais de ninhadas maiores apresentaram melhor aproveitamento da FDN após o desmame, independentemente do nível de amido. O uso de dietas mais ricas em amido antes da desmama proporcionou melhor utilização digestiva da energia, enquanto o aumento dos níveis de amido em dietas após a desmama melhorou a utilização da proteína e matéria seca.

O nível de amido mais alto fornecido antes da desmama proporcionou maior peso vivo para coelhos aos 50 e 70 dias de idade. Os animais de ninhadas contendo oito láparos apresentaram melhor conversão alimentar e menor consumo diário de ração, independentemente do nível de amido, tanto aos 50 como aos 70 dias de idade. Os resultados indicam que o consumo precoce de alimento sólido na fase de amamentação interfere nas características de desempenho após a desmama. 


\section{Literatura Citada}

BENGALA-FREIRE, J. La digestibilité totale e iléale des glicides chez le percelet sevré précocemente. Conséquences physiologiques et métaboliques. Rennes, França: Université Rennes, 1989. 150p. Thesis (Doctor).

BLAS, E.; CARMONA, F.J.; CERVERA, C. Effect of digestive activity and starch intake on amylase activity and pancreatic juice of rabbit. In: WORLD RABBIT CONGRESS, 4., 1988, Budapest. Proceedings... Budapest: 1998. v.3, p.68-73.

BLAS, E.; CERVERA, C.; CARMONA, F.J. Effect of two diets with varied starch and fibre levels on the performances of 4-7 weeks old rabbits. World Rabbit Science, v.2, n.4, p.117-121, 1994.

GIDENNE, T.; SCALABRINI, F.; MARCHAIS, C. Adaptation digestive du lapin à la teneur en constituants pariétaux du régime. Annales de Zootechnie, v.40, n.1, p.73-84, 1991.

GIDENNE, T.; PEREZ, J.M. Effect of dietary starch origin on digestión in the rabbit. 1. Digestibility measurements from weaning to slaughter. Animal Feed Science and Technology, v.42, n.3-4, p.237-242, 1993.

GIDENNE, T. Apport de fibres et d'amidon pour le lapin à l'engraissement. Cuniculture, v.23, n.1, p.18-22, 1996.

GIDENNE, T. Caeco-colic digestion in the growing rabbit: impact of nutritional factors and related disturbances. Livestestock Production Science, v.51, n.1-3, p.73-78, 1997.

GIDENNE, T., PINHEIRO, V., FALCAO, L. et al. Conséquences d'une déficience en fibres alimentaires sur la digestion et le transit: premiers résultsts chez le lapin adulte. In: JOURNÉES DE LA RECHERCHE CUNICOLE, 7., 1998, Lyon. Proceedings... Lyon: ITAVI, 1998. p.129-132.

JEHL, N.; GIDENNE, T.; LE ROUX, J.F. et al. Emploi de rations à forte proportion de fibres digestibles: effet sur la digestión et le transit du lapin en croissance. In: JOURNÉES DE LA RECHERCHE CUNICOLE, 7., 1998, Lyon. Proceedings... Lyon: ITAVI, 1998. p.137-140.

LAPLACE, J.P. Le transit digestif chez les monogastriques. III - Comportement (prise de nourriture, caecotrophie), motricité et transit digestif et pathogénie des diarrhées chez le lapin. Annales de Zootechnie, v.27, n.2, p.225-265, 1978.

LEBAS, F.; LAPLACE, J.P.; DROUMENQ, P. Efftes de la teneur en enérgie de l'aliment chez le lapin. Variations en fonction de l'âge des animaux et de la séquence des régimes alimentaires. Annales de Zootechnie, v.31, n.2, p.233-256, 1982.

LONGSTAFF, M.; McNAB, J.M. Digestion of starch and fibre carbohydrates in peas by adult cockerels. British Poultry Science, v.28, n.2, p.261-285, 1987.

MAERTENS, L.; De GROOTE, G. Feed intake of rabbit kit before weaning and attempts to increase it. Journal Applied Rabbit Research, v.13, n.3-4, p.151-158, 1990.
MATEOS, G.G.; SELL, J.L. Nature of the extrametabolic effect of supplemental fat used in semipurified diets for laying hens. Poutry Science, v.60, p.1925-1930, 1981.

MERÇIER, P. Role d'alimentare dans la pathologie digestive du lapin. La Revue Avicole, v.8, p.115-122, 1989.

McNITT, J.I.; MOODY, J. Milk intake and growth rates of sucking rabbits. Journal Applied Rabbit Research, v.11, p.117-119, 1988.

PEETERS, J.E.; POHL, P.; CHARLIER, G. et al. Infections agents associated whit diarrhea in commercial rabbits: A field study. In: WORLD RABBIT CONGRESS, 3, vol II, 1984, Roma. Proceedings... Roma: 1984. p.265-273

PEREIRA, J.R.A.; ROSSI, P. Manual prático de avaliação nutricinal de alimentos. 1.ed. Piracicaba: Fundação de Estudos Agrários Luiz de Queiroz, 1995. 34p.

PEREZ, J.M.; AUMAITRE, A. Waxy versus regular maize: energy value for growing pigs and utilization in piglet diets. Animal Feed Science Technololgy, v.4, n.2, p.109-115, 1979.

PEREZ, J.M.; LEBAS, F.; GIDENNE, T. et al. European reference method for in vivo determination of diet digestibility in rabbits. World Rabbit Science, v.3, n.1, 1995, p.41-43.

SCAPINELLO, C.; GIDENNE, T.; LAMONTHE, L. F. Digestive capacity of rabbit during the post-weaning period, according to the milk/solid feed intake pattern before weaning. Reproduction Nutrition Development, v.39, n.4, p.423432, 1999.

SILVA, D.J. Análise de alimentos (Métodos químicos e biológicos). 2.ed. Viçosa, MG: Universidade Federal de Viçosa, 1990. 165p.

UNIVERSIDADE FEDERAL DE VIÇOSA - UFV. SAEG. Sistema de análises estatísticas e genéticas. 1997, Versão 7.1. Viçosa, MG. 150p. (Manual do usuário).

XICCATO, G.; COSSU, M.E.; TROCINO, A. et al. Emploi de rations à forte proportion de fibres digestibles: effet sur la digestión et le transit du lapin en croissance. In: JOURNÉES DE LA RECHERCHE CUNICOLE, 7., 1998, Lyon, Proceedings... Lyon: ITAVI, 1998. p.159-162.

WEISEMAN, J. Assessment of the digestible and metabolizable energy of fats for non-ruminants. In: WEISEMAN, J. (Ed). Fats in animal nutrition. London: Butteworths, 1984. p.277-279.

YUTSTE, P., LONGSTAFF, M.A.; McNAB, J.M. et al. The digestibility of semipurified starchs from wheat, cassava, pea, bean and potato by adult cockerels and young chicks. Animal Feed Science Technology, v.35, n.3-4, p.289-300, 1991.

Recebido em: 28/07/03 Aceito em: 03/12/03 